\title{
Mucosa-associated lymphoid tissue lymphoma arising from the kidney
}

\author{
Naoya Niwa, MD;* Nobuyuki Tanaka, MD; Minoru Horinaga, MD;* Hiroshi Hongo, MD; ${ }^{*}$ Yujiro Ito, MD;* Takuro \\ Watanabe, MD; ${ }^{\dagger}$ Takeshi Masuda, MD*
}

*Department of Urology, Saitama City Hospital, Japan; †Department of Hematology, Saitama City Hospital, Japan

Cite as: Can Urol Assoc J 2014;8(1-2):e86-8. http://dx.doi.org/10.5489/cuaj.1533 Published online February 12, 2014.

\section{Abstract}

Primary renal lymphoma is rare, and most are intermediate- and high-grade lymphomas of B-cell lineage, such as diffuse large B-cell or Burkitt lymphoma. We report a case of low-grade B-cell lymphoma of the mucosa-associated lymphoid tissue (MALT) arising from the kidney. Only a few cases of primary renal MALT lymphoma have been published.

\section{Introduction}

Primary renal lymphoma (PRL) is rare, and most are intermediate- and high-grade lymphomas of B-cell lineage, such as diffuse large B-cell or Burkitt lymphoma. ${ }^{1}$ Low-grade B-cell lymphoma of the mucosa-associated lymphoid tissue (MALT) arising from the kidney is extremely rare. We describe the case of an 86-year-old woman who presented with a right renal mass. Radical right nephroureterectomy revealed a primary renal MALT lymphoma. Although the management of primary renal MALT lymphoma has not yet been established, surgical treatment alone may be effective, as demonstrated in our case.

\section{Case report}

An 86-year-old woman was referred to the Department of Urology because a right renal mass was incidentally detected by ultrasonography during her hospital admission for urinary tract infection a month before. Her medical history was unremarkable, except for type 2 diabetes mellitus managed with subcutaneous insulin injections. On physical examination, she had no palpable flank or abdominal masses and no appreciable lymphadenopathy and hepatosplenomegaly. The urine cytological examination result was negative (class 2). A complete blood count revealed anemia (hemoglobin level, $9.7 \mathrm{~g} / \mathrm{dL}$ ), with normal white blood cell and platelet counts. A biochemistry examination revealed elevated levels of serum creatinine $(1.13 \mathrm{mg} / \mathrm{dL})$ and soluble interleukin-2 receptor $(665 \mathrm{U} / \mathrm{mL}$; range: $145-519 \mathrm{U} / \mathrm{mL})$. A contrast-enhanced computed tomographic (CT) scan showed an infiltrative mass arising from the lower pole of the right kidney without any nodal involvement. The infiltrative mass was enhanced much lower than the renal parenchyma (Fig. 1). A right renal pelvic tumour was suspected; thus, ureteroscopy was performed under general anesthesia. The tumour was covered by smooth urothelial mucosa, and a biopsy was performed. A pathological examination revealed no evidence of malignancy. After 4 months, a repeat nonenhanced CT was performed, revealing a growing tumour. Given that renal pelvic carcinoma could not be excluded, laparoscopic radical nephroureterectomy was performed after obtaining written informed consent from the patient.

Grossly, the specimen contained a yellowish, ill-defined, soft, and solid tumour infiltrating the renal parenchyma. On microscopic examination, the tumour was composed of small uniform lymphoid cells diffusely infiltrating the renal parenchyma (Fig. 2. Part A) and perirenal fat (Fig. 2, part B). The neoplasms were predominantly composed of small-tomedium lymphoid cells with slightly irregular nuclear contours, and plasma cells with characteristic cartwheel nuclei and perinuclear halos were scattered (Fig. 2, part C). Large atypical lymphoid cells with high nuclear-cytoplasmic ratio and apoptosis, indicating transformation into an aggressive lymphoma such as diffuse large B-cell lymphoma, were partly observed (Fig. 2, part D). The neoplastic lymphoid cells were positive for CD20 and CD79a but negative for CD3, CD4, CD5, CD8, CD10, CD30 and Bcl-2. The pathological diagnosis was low-grade B-cell lymphoma of the mucosaassociated lymphoid tissue (MALT), with partial transformation into a diffuse large B-cell lymphoma.

Additional postoperative examinations were performed. Bone marrow aspiration and biopsy revealed no morphological involvement of lymphoma, and positron-emission 


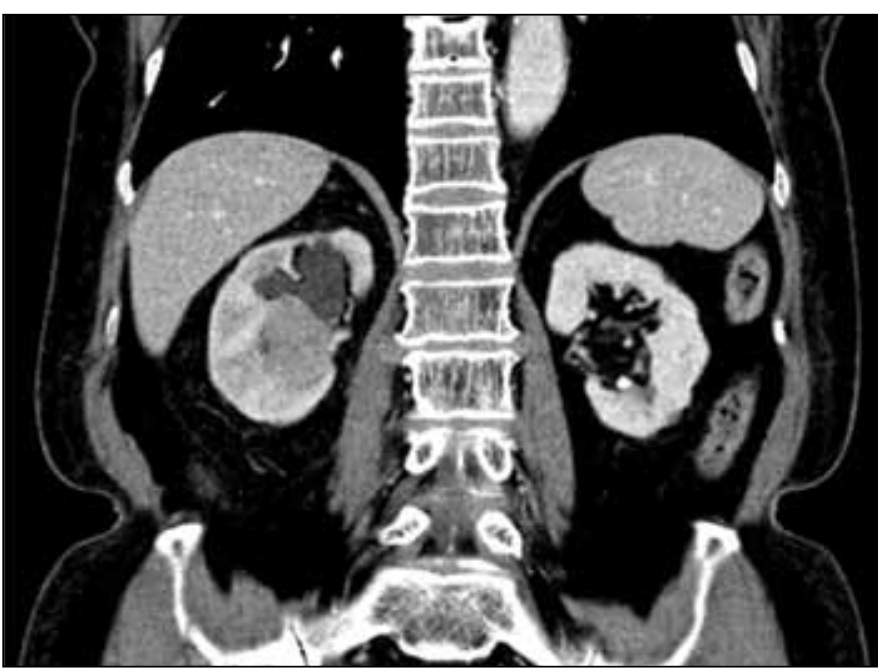

Fig. 1. Contrast-enhanced computed tomographic scan showing an infiltrative mass arising in the lower pole of the right kidney.

tomographic CT revealed no abnormally increased uptake of ${ }^{18} \mathrm{~F}$-fluorodeoxyglucose in the nodules or other organs.

The patient was diagnosed with localized MALT lymphoma arising from the kidney. No additional treatment was given, and the patient was disease-free 4 months after surgery.

\section{Discussion}

Although the incidence of secondary renal involvement with systemic non-Hodgkin lymphoma (NHL) is high, PRL is rare. ${ }^{2}$ One reason for the low incidence of PRL is that the kidney does not contain lymphatic tissue. ${ }^{3}$ Most PRLs are classified as intermediate- and high-grade B-cell lymphomas, such as diffuse large B-cell lymphoma, ${ }^{3}$ and low-grade $P R L$, including MALT lymphoma, is extremely rare. MALT lymphoma, also called extranodal marginal zone lymphoma of the MALT, arises in a number of epithelial tissues; this most area are the gastric, ocular, bowel, pulmonary and salivary glands. ${ }^{4}$

PRL is defined as a lymphoma arising primarily in the renal parenchyma, not resulting from invasion of an adjacent lymphomatous mass. ${ }^{1}$ The diagnosis of PRL is challenging. Although clear diagnostic criteria have not yet been established, it is mandatory to obtain kidney specimens obtained by renal biopsy or nephrectomy, a bone marrow biopsy and an imaging study, such as thoracoabdominal CT, to exclude the presence of other extranodal lesions. ${ }^{5}$ These diagnostic procedures may underestimate the incidence of PRL, since PRLs are usually intermediate- and high-grade B-cell NHLs that metastasize rapidly. It is also essential to distinguish PRLs from other malignancies, such as renal cell carcinoma and pelvic urothelial carcinomas. Although CT-guided percutaneous renal tumour biopsy is useful for

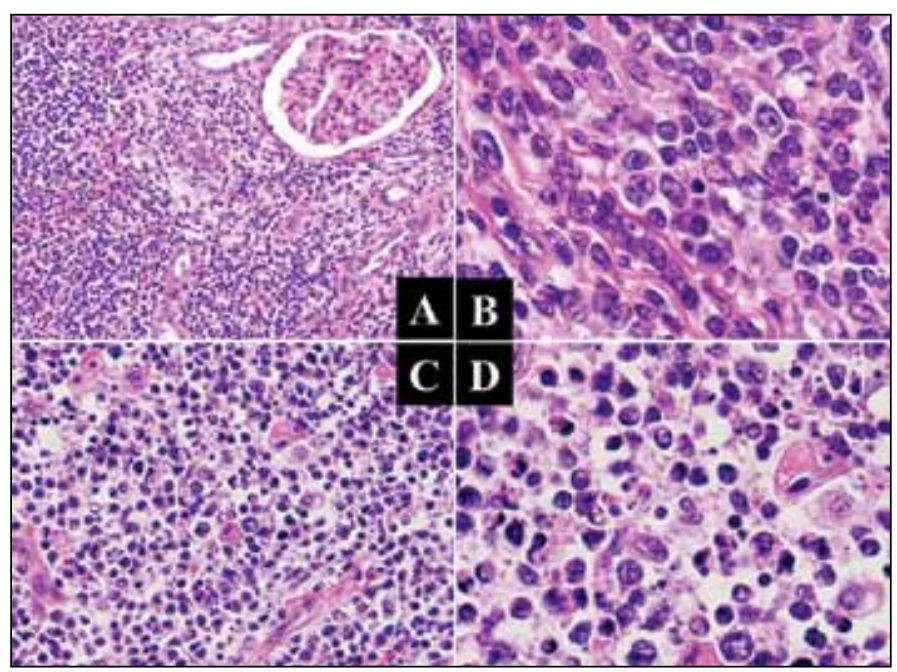

Fig. 2. A: The tumour composed of small uniform lymphoid cells diffusely infiltrating the renal parenchyma (hematoxylin-eosin [H\&E] staining, original magnification $\times 100$ ). B: The tumour infiltrating the perirenal fat (H\&E staining, original magnification $\times 100$ ). C: The small to medium neoplastic lymphoid cells with slightly irregular nuclear contours and plasma cells (H\&E staining, original magnification $\times 400$ ). D: The large atypical lymphoid cells with high nuclear-cytoplasmic ratio and apoptosis that were also observed (H\&E original magnification $\times 400$ ).

accurate histopathological diagnosis, it should not be performed if a urothelial carcinoma is suspected because of the risk of biopsy tract seeding. ${ }^{6}$

Although the management of MALT lymphoma arising from the kidney has not been established, MALT-type lymphoma have a striking tendency to be localized at diagnosis and may be cured with local therapy. ${ }^{7}$ The 5 -year overall survival and incidence reports of lymphoma-related death of patients with MALT lymphomas arising in the genitourinary tract were $75.6 \%$ and $12.4 \%$, respectively. ${ }^{4}$ Meanwhile, those of MALT lymphoma with different anatomical origins ranged from $69.1 \%$ to $87.9 \%$ and from $4.5 \%$ to $17.3 \%$, respectively. ${ }^{4}$ Although the accurate prognosis of patients with MALT lymphoma arising from the kidney is unknown, they may be within the aforementioned ranges. Some cases of renal MALT lymphoma without any postoperative recurrence have been reported..$^{7-9}$ Considering our patient's age, the adverse events during chemotherapy administration and the good prognosis, we decided to closely monitor the patient's condition without additional treatment.

Competing interests: Dr. Niwa, Dr. Tanaka, Dr. Horinaga, Dr. Hongo, Dr. Ito, Dr. Watanabe, Dr. Masuda all declare no competing financial or personal interests.

This paper has been peer-reviewed. 
Niwa et al.

\section{References}

1. Okuno SH, Hoyer JD, Ristow K, et al. Primary renal non-Hodgkin's lymphoma: An unusual extranodal site. Cancer 1995;75:2258-61.

2. Kandel LB, McCullough DL, Harrison LH, et al. Primary renal lymphoma: Does it exist? Cancer 1987;60:386-91. http://dx.doi.org/10.1002/1097-0142(19870801)60:3<386::AlDCNCR2820600317>3.0.C0;2-4

3. Farrow GM, Harrison EG Jr, Utz DC. Sarcomas and sarcomatoid and mixed malignant tumors of the kidney in adults. 3. Cancer 1968;22:556-63. http://dx.doi.org/10.1002/1097-0142(196809)22:3<556:AlDCNCR2820220310>3.0.C0;2-N

4. Olszewski AJ, Castillo JJ. Survival of patients with marginal zone lymphoma: Analysis of the Surveillance, Epidemiology, and End Results database. Cancer 2013;119:629-38. http://dx.doi.org/10.1002/ cncr. 27773
5. Stallone $G$, Infante B, Manno C, et al. Primary renal lymphoma does exist: Case report and review of the literature. J Nephrol 2000;13:367-72.

6. Herts BR. Imaging guided biopsies of renal masses. Curr Opin Urol 2000;10:105-9. http://dx.doi. org/10.1097/00042307-200003000-00010

7. Tuzel E, Mungan MU, Yorukoglu K, et al. Primary renal lymphoma of mucosa-associated lymphoid tissue. Urology 2003;61:463. http://dx.doi.org/10.1016/S0090-4295(02)02267-7

8. Qiu L, Unger PD, Dillon RW, et al. Low-grade mucosa-associated lymphoid tissue lymphoma involving the kidney: Report of 3 cases and review of the literature. Arch Pathol Lab Med 2006;130:86-9.

9. Kato $Y$, Hasegawa M, Numasato $S$, et al. Primary mucosa-associated lymphoid tissue-type lymphoma arising in the kidney. Int J Urol 2008; 15:90-2. http://dx.doi.org/10.1111/i.1442-2042.2007.01923.x

Correspondence: Dr. Naoya Niwa, Department of Urology, Keio University School of Medicine, Japan; ashandjesus@gmail.com 